\title{
Multi-Objectives Finite Capacity Scheduling of Make-and- Pack Production with Options to Adjust Processing Time
}

\author{
Sophea Horng ${ }^{1}$ and Pisal Yenradee ${ }^{2}$ \\ ${ }^{1}$ Master of Engineering Student, Logistics and Supply Chain Systems Engineering Program, School of Manufacturing \\ Systems and Mechanical Engineering, Sirindhorn International Institute of Technology, Thammasat University, Pathum \\ Thani, 12121, Thailand. Email: horngsophea@yahoo.com \\ ${ }^{2}$ Associate Professor, Logistics and Supply Chain Systems Engineering Program, School of Manufacturing Systems and \\ Mechanical Engineering, Sirindhorn International Institute of Technology, Thammasat University, Pathum Thani, 12121, \\ Thailand. Email: pisal@ siit.tu.ac.th (corresponding author).
}

\author{
Production Management \\ Received January 27, 2014; received revision April 21, 2014; accepted on May 7, 2014 \\ Available online May 22, 2014
}

\begin{abstract}
Make-and-pack production is characterized by two stages of production namely, "make-stage" and "packstage" where each stage consists of parallel processing units. In make-stage, raw materials are converted into final products by batch processing. Then, the final products are packed into containers in pack-stage. This paper develops finite capacity scheduling (FCS) system of make-and-pack production with multi-objectives and options to adjust processing time (OAPT). Multi-objectives including minimizations of total tardiness, total earliness, total flow time, and total processing costs are conflicting and a compromised solution is needed. Moreover, the processing time can be adjusted by adding some special chemicals. This paper proposes mixed-integer linear programming models to determine the compromised solution by using weighted average of satisfaction levels (WASL) of all objectives as performance measure. The proposed compromised solution method consists of three steps, (1) determining the best and worst values of each objective, (2) determining the initial compromised solution of all objectives when OAPT is not included in the model, and (3) determining the compromised solution with OAPT. The effect of chemical costs to the OAPT is evaluated. The results showed that the proposed FCS system offered a compromised solution between conflicting objectives. The compromised solution is relatively good but not the best for all objectives. The OAPT can improve the performance of the system and it is significantly affected by the chemical cost per unit. When the chemical cost per unit is reduced, the special chemical is used more to reduce processing time per batch and then the performance measure is more improved.
\end{abstract}

Keywords: Make-and-pack production, mixed-integer linear programming, multi-objectives, compromised solution, adjustable processing times.

\section{Introduction}

In the chemical industry, make-and-pack production is classified as multistage processes where batches are processed in a sequence of stages from make-stage to pack-stage. Honkomp et al. (2000) presented the case study of make-and-pack production process which is characterized by two stages of production namely, "makestage" and "pack-stage". Each stage consists of parallel processing units. In make-stage, raw materials are converted into final products by batch processing. Then, the final products are packed into containers in pack-stage. The decisions that are needed to be made to schedule make-and-pack production include batch selection, batch sizing, batch assignment, batch sequencing and timing.

Scheduling system is the decision-making process that attempts to optimize one or more objectives by allocating limited resources to competing jobs over time. A buffer size determination is an important issue in scheduling decision. Ko and Chen (2012) evaluated production time buffer for precast fabrication using fuzzy logic system considering factors that influence construction duration.

Most scheduling systems of make-and-pack production developed by previous research works have the following limitations. First, they perform machine loading \& scheduling, and batch selection \& sizing separately. When these two decisions are not performed simultaneously, this will lead to suboptimal solutions. Second, the scheduling systems have single objective or many conflicting objectives but each objective is considered separately. They do not try to compromise among conflicting objectives. Third, they do not consider an option to add some special chemicals to reduce processing time. When the system has many tardy jobs, it is very beneficial to reduce the processing time by adding some chemicals to a certain extent to speed up chemical reaction. Although, this action increases chemical cost but it reduces tardiness of jobs significantly. 
The purpose of this paper is to reduce the abovementioned limitations. Firstly, we develop the finite capacity scheduling system of make-and-pack production that can provide the compromised solution for multiple conflicting objectives. Secondly, the system can perform machine loading \& scheduling, and batch selection \& sizing simultaneously. Thus this will not lead to suboptimality. Thirdly, the options to adjust processing time (OAPT) by adding some chemicals during the make-stage are then introduced to improve the system performances after the initial compromised solution is determined.

The paper is organized as follows. In section 2 , the developments of scheduling system of multistage production processes that are related to make-and-pack production are reviewed, and the research gaps are identified. The development of model formulations is presented in section 3. Section 4 illustrates the method for determining the compromised solution of the scheduling system. A case study for evaluating the proposed scheduling system is given in section 5. In section 6, results are discussed. Finally, section 7 presents the conclusions of the paper and possible further studies.

\section{Literature Reviews}

In this section, the developments of scheduling systems that are related to make-and-pack production processes are reviewed. The reviews are mostly related to the developments of scheduling system with mixed-integer linear programming (MILP) models because this paper focuses on this approach. In the scheduling systems, there are two problems, namely batching and scheduling problems that must be solved. The batching problem decides number of batches and batch size while the scheduling problem determines the assignment of products to processing units and their sequence and timing. The scheduling systems are divided into two groups. The first group, the batching problem is independently solved in advance of the scheduling problem. The second group, both problems are solved simultaneously. It is clear that the second group can offer better solution but the computational time is longer.

Research works that belongs to the first group are as follows. Fündeling and Trautmann (2006) proposed a priority-based heuristic to compute schedule for makeand-pack production that was presented by Honkomp et al. (2000). In this method, the technological constraints are used to determine the assignments and the sequences of production orders. An MILP model was proposed with block-planning concept by Günther et al. (2006). A block represents a pre-defined sequence of production orders of variable sizes. Méndez and Cerdá (2002) developed MILP formulation that is applied for scheduling of make-andpack continuous production plant in a make-to-stock environment. The assignment and sequencing decisions are handled independently. Baumann and Trautmann (2011) also developed scheduling system for a make-andpack production with a continuous-time MILP model. The assignment, sequencing, and timing of production batches are determined simultaneously. Then the model was modified to cover all the technological constraints (Baumann and Trautmann, 2013). Méndez et al. (2006) has reviewed the optimization methods for short-term scheduling of batch processes and introduced the optimization approaches for the different problem types, focusing on both discrete and continuous-time models.
The second group of research works that simultaneously solve batching and scheduling problems are as follows. The simultaneous batching and scheduling system with MILP formation models were presented by Prasad et al. (2006), Prasad and Maravelias (2008), and Sundaramoorthy and Maravelias (2008a, 2008b). Castro and Novais (2008) presented a multiple time grid formulation that is based on the resource-task network process representation. It is the extended work of Castro and Grossmann (2005). Marchetti et al. (2012) developed a pair of MILP formulations and one of them has been specially designed for solving very large scheduling problems. Both approaches can schedule multiple orders for the same product that due at different delivery dates. They allow splitting a batch of final product to satisfy more than one order. In these researches, all decisions for both problems are included in a single MILP model.

The methods that were previously developed involved single objective optimization. However, some of those methods mentioned alternative objectives where those are optimized separately. Prasad et al. (2006) suggested multiple factors in the objective function of the model but those factors are not conflicting with each other.

Based on the literature survey, we found limitations of the previous works as follows. Most research works consider batching and scheduling problems separately that may result in sub-optimal solution. They do not try to determine the compromised solution among many conflicting objectives. Finally, they do not consider a decision to add special chemicals to reduce processing time of make-stage. These limitations will be reduced by the proposed scheduling method.

\section{Model Formulations}

In this section, there are descriptions of notations, problem statement and assumptions of make-and-pack production processes, parameters preparation, constraints, and objective functions of models.

\subsection{Notations}

\subsubsection{Sets and subsets}

F Set of factors where $\mathrm{F}=\{\mathrm{TEN}, \mathrm{TTN}, \mathrm{TFT}, \mathrm{TPC}\}$

I Set of orders where $I=\{1,2, \ldots,|\mathrm{I}|\}$

J Set of units where $J=\{1,2, \ldots,|J|\}$

$\mathrm{J}_{\mathrm{s}} \quad$ Set of units in stage $\mathrm{s}$ where $\mathrm{J}=\mathrm{J}_{1} \cup \mathrm{J}_{2} \cup . . \cup \mathrm{J}_{|\mathrm{s}|}$

S Set of stages where $S=\{1,2, \ldots,|S|\}$

$\mathrm{JA}_{\mathrm{is}} \quad$ Set of allowable units for order $\mathrm{i}$ in stage $\mathrm{s}$ where $\mathrm{JA}_{\text {is }}=\mathrm{J}_{\mathrm{S}} \backslash J \mathrm{~F}_{\text {is }}$

$\mathrm{JF}_{\text {is }} \quad$ Set of forbidden units for order $\mathrm{i}$ in stage $\mathrm{S}$

FP Set of forbidden path between units $\mathrm{j}$ and $\mathrm{j}^{\prime}$

L Set of batches where $\mathrm{L}=\{1,2, \ldots, \mathrm{LMAX}\}$

$\mathrm{L}_{\mathrm{i}}$ Set of batches of order $\mathrm{i}$ where $\mathrm{L}_{\mathrm{i}}=$ $\left\{1,2, \ldots, \operatorname{Lmax}_{\mathrm{i}}\right\}$

IL Set of pairs of batches $(\mathrm{i}, \mathrm{l})$ and $\left(\mathrm{i}^{\prime}, \mathrm{l}^{\prime}\right)$ that can be sequenced where $\mathrm{IL}=\left\{\mathrm{i}, \mathrm{i}^{\prime}, \mathrm{l} \in \mathrm{L}_{\mathrm{i}}, \mathrm{l}^{\prime} \in \mathrm{L}_{\mathrm{i}^{\prime}}\right.$ :

$\left.\left(i \neq i^{\prime}\right) \cup\left(\left(i=i^{\prime}\right) \cap\left(l \neq l^{\prime}\right)\right)\right\}$ 


\subsubsection{Parameters}

$\mathrm{Q}_{\mathrm{i}} \quad$ The demand of order i $(\mathrm{kg})$

$r_{i} / d_{i} \quad$ The release/due time of order $\mathrm{i}(\mathrm{hr})$

$\operatorname{bmin}_{\mathrm{j}} \quad$ The minimum operational capacity of unit $\mathrm{j}(\mathrm{kg})$

$\operatorname{bmax}_{j}$ The maximum operational capacity of unit $\mathrm{j}(\mathrm{kg})$

$\mathrm{Bmin}_{\mathrm{i}}$ The minimum feasible batch size of order $\mathrm{i}(\mathrm{kg})$

$\operatorname{Bmax}_{\mathrm{i}}$ The maximum feasible batch size of order $\mathrm{i}(\mathrm{kg})$

$\operatorname{Lmin}_{\mathrm{i}}$ The minimum potential number of batches of order i (unitless)

$\operatorname{Lmax}_{\mathrm{i}}$ The maximum potential number of batches of order i (unitless)

LMAX The maximum number of batches for all orders (unitless)

$\mathrm{Ft}_{\mathrm{ij}} \quad$ The fixed processing time of order $\mathrm{i}$ in unit $\mathrm{j}$ (hr/kg)

$\mathrm{Pt}_{\mathrm{ij}} \quad$ The proportional processing time of order $\mathrm{i}$ in unit j (hr/kg)

$\mathrm{FC}_{\mathrm{ij}} \quad$ The fixed processing cost of order $\mathrm{i}$ in unit $\mathrm{j}(\$ / \mathrm{hr})$

$\mathrm{Pc}_{\mathrm{ij}} \quad$ The proportional processing cost of order $\mathrm{i}$ in unit j $(\$ / h r)$

$\operatorname{Min}_{\mathrm{f}}$ The minimum value of factor $\mathrm{f}$ (depend on factor $\mathrm{f}$ )

$\operatorname{Max}_{\mathrm{f}}$ The maximum value of factor $f$ (depend on factor $\mathrm{f}$ )

MaxWASL The initial maximum weighted average of satisfaction levels (unitless)

M The big M value (unitless)

$\mathrm{Cc}_{\mathrm{i}} \quad$ The chemical cost per unit of order i $(\$ / \mathrm{kg})$

$\operatorname{Pr}_{\mathrm{i}} \quad$ The reduction rate of proportional processing time of order i (unitless)

$\mathrm{w}_{\mathrm{f}} \quad$ The assigned weight of satisfaction level for factor $\mathrm{f}$ (unitless)

\subsubsection{Independent variables}

$Z_{\mathrm{il}} \quad$ The selection of batch (i,l) (binary); $Z_{\mathrm{il}}=1$ if batch $(i, l)$ is selected

$\mathrm{X}_{\mathrm{ilj}} \quad$ The assignment of batch $(\mathrm{i}, \mathrm{l})$ to unit $\mathrm{j}$ (binary); $X_{i l j}=1$ if batch $(i, l)$ is assigned to unit $j$

$Y_{\text {ili'l's }}{ }^{\prime}$ The pairwise sequencing between batches (i,l) and $\left(\mathrm{i}^{\prime}, \mathrm{l}^{\prime}\right)$ in stage $\mathrm{s}$ (binary); $\mathrm{Y}_{\mathrm{ili}^{\prime} \mathrm{l}^{\prime} \mathrm{s}}=1$ if batch $(\mathrm{i}, \mathrm{l})$ is processed before (not necessary immediately before) batch $\left(i^{\prime}, l^{\prime}\right)$ in unit $j$ of stage S

$\mathrm{AC}_{\mathrm{ilj}}$ The addition of chemical to batch (i, l) in unit $\mathrm{j}$ (binary); $\mathrm{AC}_{\mathrm{ilj}}=1$ if chemical is added to batch $(i, l)$ in unit $j$

$\mathrm{Ba}_{\mathrm{il}} \quad$ The size of batch $(\mathrm{i}, \mathrm{l})(\mathrm{kg})$

$\mathrm{Bb}_{\mathrm{ilj}} \quad$ The size of batch $(\mathrm{i}, \mathrm{l})$ processed in unit $\mathrm{j}(\mathrm{kg})$

$\mathrm{F}_{\mathrm{ils}} \quad$ The finished time of batch $(\mathrm{i}, \mathrm{l})$ in stage $\mathrm{s}(\mathrm{hr})$

\subsubsection{Dependent variables}

Earl $_{\text {il }}$ The earliness of batch (i, l) (hr)

$\operatorname{Tard}_{\mathrm{il}}$ The tardiness of batch (i,l) (hr)

Flow $_{\text {il }}$ The flow time of batch (i, l) (hr)

\subsubsection{Performance measures}

TEN The total earliness (hr)

TTN The total tardiness (hr)

TFT The total flow time (hr)

TPC The total processing cost (\$)

$\mathrm{SL}_{\mathrm{f}} \quad$ The satisfaction level of factor $\mathrm{f}$ (unitless)

WASL The weighted average of satisfaction levels (unitless)

\subsection{Problem Statement and Assumptions}

The model formulations are based on the following characteristics of make-and-pack production processes. (1) There is a set of orders with demand quantity, release and due times. (2) There is a set of processing units with minimum/maximum operational capacities, fixed/ proportional processing times, and fixed/proportional processing costs. (3) There is a set of stages and in each stage there is a set of parallel (identical or non-identical) processing units. (4) There are sets of allowable units and forbidden units for each order in each stage, and forbidden path between processing units of each stage for all orders.

The assumptions for the production system are as follows. (1) All orders are known and available at the beginning of the planning horizon. (2) All of the raw materials are available with sufficient quantity. (3) All batches visit all stages. (4) The storage tanks for products are unlimited. (5) Changeover time is not sequence dependent. Thus it is assumed to be part of the processing time. (6) Quality release time (for quality inspection) is not considered. The successor operation can be started immediately if there is available processing unit. (7) All of the operations are non-preemptive.

\subsection{Parameters Preparations}

When minimum $\left(\operatorname{bmin}_{j}\right)$ and $\operatorname{maximum}\left(\operatorname{bmax}_{j}\right)$ capacities of each processing unit, and demand $\left(Q_{i}\right)$ of each order are given, the parameters of minimum $\left(\mathrm{Bmin}_{\mathrm{i}}\right)$ and maximum $\left(\mathrm{Bmax}_{\mathrm{i}}\right)$ feasible batch sizes, and minimum $\left(\operatorname{Lmin}_{\mathrm{i}}\right)$ and maximum $\left(\operatorname{Lmax}_{\mathrm{i}}\right)$ numbers of batches and maximum (LMAX) number of batch for all orders can be predetermined and used as parameters of models, Eqs. (1)-(5).

$$
\begin{aligned}
& \operatorname{Bmin}_{\mathrm{i}}=\max _{\mathrm{s} \in \mathrm{S}}\left[\min _{\mathrm{j} \in \mathrm{J} A_{\mathrm{is}}}\left(\mathrm{bmin}_{\mathrm{j}}\right)\right] ; \forall \mathrm{i} \in \mathrm{I} \\
& \operatorname{Bmax}_{\mathrm{i}}=\min _{\mathrm{s} \in \mathrm{S}}\left[\max _{\mathrm{j} \in \mathrm{JA} \mathrm{A}_{\mathrm{is}}}\left(\operatorname{bmax}_{\mathrm{j}}\right)\right] ; \forall \mathrm{i} \in \mathrm{I} \\
& \operatorname{Lmin}_{\mathrm{i}}=\left\lceil\mathrm{Q}_{\mathrm{i}} / \mathrm{Bmax}_{\mathrm{i}}\right\rceil ; \forall \mathrm{i} \in \mathrm{I} \\
& \operatorname{Lmax}_{\mathrm{i}}=\left\lceil\mathrm{Q}_{\mathrm{i}} / \mathrm{Bmin}_{\mathrm{i}}\right\rceil ; \forall \mathrm{i} \in \mathrm{I} \\
& \operatorname{LMAX}=\max _{\mathrm{i} \in \mathrm{I}}\left(\operatorname{Lmax}_{\mathrm{i}}\right)
\end{aligned}
$$




\subsection{Constraints}

The MILP formulation models of make-and-pack production are constrained by conditions as follows.

Condition 1: Demand Satisfaction. The production quantity must satisfy the customer demand for all orders, Eq. (6).

$$
\sum_{\mathrm{l} \in \mathrm{L}_{\mathrm{i}}} \mathrm{Ba}_{\mathrm{il}}=\mathrm{Q}_{\mathrm{i}} ; \forall \mathrm{i} \in \mathrm{I}
$$

Condition 2: Batch Selection and Batch Assignment. If batch $(\mathrm{i}, \mathrm{l})$ is selected, it must be assigned to only one processing unit $\mathrm{j}$ in each stage $\mathrm{s}$, Eq. (7). Then size of batch $(i, l)$ must be between the minimum and maximum operational capacities of that processing unit, Eqs. (8), (9).

$$
\begin{gathered}
\mathrm{Z}_{\mathrm{il}}=\sum_{\mathrm{j} \in \mathrm{JA}_{\mathrm{is}}} \mathrm{X}_{\mathrm{ilj}} ; \forall \mathrm{i} \in \mathrm{I}, \mathrm{l} \in \mathrm{L}_{\mathrm{i}}, \mathrm{s} \in \mathrm{S} \\
\mathrm{Ba}_{\mathrm{il}}=\sum_{\mathrm{j} \in \mathrm{JA}_{\mathrm{is}}} \mathrm{Bb}_{\mathrm{ilj}} ; \forall \mathrm{i} \in \mathrm{I}, \mathrm{l} \in \mathrm{L}_{\mathrm{i}}, \mathrm{s} \in \mathrm{S} \\
\operatorname{bmin}_{\mathrm{j}} \mathrm{X}_{\mathrm{ilj}} \leq \mathrm{Bb}_{\mathrm{ilj}} \leq \operatorname{bmax}_{\mathrm{j}} \mathrm{X}_{\mathrm{ilj}} ; \\
\forall \mathrm{i} \in \mathrm{I}, \mathrm{l} \in \mathrm{L}_{\mathrm{i}}, \mathrm{s} \in \mathrm{S}, \mathrm{j} \in \mathrm{JA}_{\mathrm{is}}
\end{gathered}
$$

Condition 3: Symmetry Breaking Purposes. This condition is used to restrict the selection and sizing of potential batches. For order i, a smaller batch number must be selected before a larger batch number can be selected, Eq. (10). The batch size of a larger batch number is not allowed to exceed that of a smaller batch number, Eq. (11).

$$
\begin{gathered}
\mathrm{Z}_{\mathrm{i}(\mathrm{l}-1)} \geq \mathrm{Z}_{\mathrm{il}} ; \forall \mathrm{i} \in \mathrm{I}, \mathrm{l} \in \mathrm{L}_{\mathrm{i}} \backslash\{1\} \\
\mathrm{Ba}_{\mathrm{i}(\mathrm{l}-1)} \geq \mathrm{Ba}_{\mathrm{il}} ; \forall \mathrm{i} \in \mathrm{I}, \mathrm{l} \in \mathrm{L}_{\mathrm{i}} \backslash\{1\}
\end{gathered}
$$

Condition 4: Batch Sequence. When two batches (i, l) and $\left(\mathrm{i}^{\prime}, \mathrm{l}^{\prime}\right)$ are processed in the same unit $\mathrm{j}$ in stage $\mathrm{s}$, both batches have to follow the sequence either batch $(\mathrm{i}, \mathrm{l})$ or $\left(\mathrm{i}^{\prime}, \mathrm{l}^{\prime}\right)$ is processed first because both batches cannot be processed in the same unit at the overlapped time, Eq. (12).

$$
\begin{gathered}
\mathrm{X}_{\mathrm{ilj}}+\mathrm{X}_{\mathrm{i}^{\prime} \mathrm{l}^{\prime} \mathrm{j}}-1=\mathrm{Y}_{\mathrm{ili} \mathrm{i}^{\prime} \mathrm{l}^{\prime} \mathrm{s}}+\mathrm{Y}_{\mathrm{i}^{\prime} \mathrm{l}^{\prime} \mathrm{ils}} ; \\
\forall\left(\mathrm{i}, \mathrm{l}, \mathrm{i}^{\prime}, \mathrm{l}^{\prime}\right) \in \mathrm{IL}, \mathrm{i} \leq \mathrm{i}^{\prime}, \mathrm{s} \in \mathrm{S}, \mathrm{j} \in \mathrm{JA}_{\mathrm{is}} \cap \mathrm{JA}_{\mathrm{i}^{\prime} \mathrm{s}}
\end{gathered}
$$

Condition 5: Non-Overlapping Processing Times of Batches. In the same stage $\mathrm{s}$ when the batch $\left(\mathrm{i}^{\prime}, \mathrm{l}^{\prime}\right)$ is sequenced to process after the batch $(i, l)$ the finished time of batch $\left(\mathrm{i}^{\prime}, \mathrm{l}^{\prime}\right)$ is after batch $(\mathrm{i}, \mathrm{l})$ is finished plus the processing times of batch $\left(\mathrm{i}^{\prime}, \mathrm{l}^{\prime}\right)$ in that stage, Eq. (13). Between two consecutive stages, the finished time of batch $(\mathrm{i}, \mathrm{l})$ in stage $(\mathrm{s}+1)$ is after it is finished from stage $\mathrm{s}$ plus its processing times in stage $(s+1)$, Eq. (14). The finished time of batch $(\mathrm{i}, \mathrm{l})$ in the first stage is after its release time plus its processing time in the first stage, Eq. (15).

$$
\begin{aligned}
\mathrm{F}_{\mathrm{i}^{\prime} \mathrm{l}^{\prime} \mathrm{s}} \geq & \mathrm{F}_{\mathrm{ils}}+\sum_{\mathrm{j} \in \mathrm{JA_{ \textrm {i } ^ { \prime } \mathrm { s } }}}\left(\mathrm{Ft}_{\mathrm{i}^{\prime} \mathrm{j}} \mathrm{X}_{\mathrm{i}^{\prime} \mathrm{l}^{\prime} \mathrm{j}}+\mathrm{Pt}_{\mathrm{i}^{\prime} \mathrm{j}} \mathrm{Bb}_{\mathrm{i}^{\prime} \mathrm{l}^{\prime} \mathrm{j}}\right) \\
& +\mathrm{M}\left(1-\mathrm{Y}_{\mathrm{ili} \mathrm{i}^{\prime} \mathrm{l}^{\prime} \mathrm{s}}\right) ; \forall\left(\mathrm{i}, \mathrm{l}, \mathrm{i}^{\prime}, \mathrm{l}^{\prime}\right) \in \mathrm{IL}, \mathrm{s} \in \mathrm{S}
\end{aligned}
$$

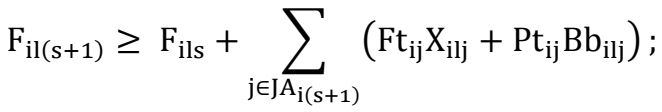

$$
\begin{aligned}
& \forall \mathrm{i} \in \mathrm{I}, \mathrm{l} \in \mathrm{L}_{\mathrm{i}}, \mathrm{s}<|\mathrm{S}| \\
& F_{i l 1} \geq r_{i} Z_{i l}+\sum_{j \in J A_{i 1}}\left(F t_{i j} X_{i l j}+P t_{i j} B b_{i l j}\right) \text {; } \\
& \forall \mathrm{i} \in \mathrm{I}, \mathrm{l} \in \mathrm{L}_{\mathrm{i}}
\end{aligned}
$$

Condition 6: Forbidden Units and Forbidden Path. The batch $(\mathrm{i}, \mathrm{l})$ is not allowed to be assigned to forbidden units for order i in stage s, Eq. (16). The batch (i,l) is allowed to be assigned to at most one processing unit of forbidden paths between two consecutive stages, Eq. (17).

$$
\begin{gathered}
X_{\text {ilj }}=0 ; \forall i \in I, l \in L_{i}, s \in S, j \in J F_{i s} \\
X_{i l j}+X_{i_{1 j}} \leq Z_{i l} ; \forall i \in I, l \in L_{i},\left(j, j^{\prime}\right) \in F P
\end{gathered}
$$

Condition 7: Minimum Numbers of Batch Selection. At least the minimum numbers of batches must be selected to satisfy, Eq. (18).

$$
\mathrm{Z}_{\mathrm{il}}=1 ; \forall \mathrm{i} \in \mathrm{I}, \mathrm{l} \leq \operatorname{Lmin}_{\mathrm{i}}
$$

Condition 8: Earliness, Tardiness, and Flow Time Computations. When either earliness or tardiness is involved in the objective function, the earliness and tardiness can be computed in the model, Eq. (19). However, when earliness and tardiness are both excluded, these values have to be computed outside the model, Eqs. (19a), (19b). Flow time of batch $(i, l)$ is the different between finished time of last stage and started time of first stage, Eq. (20).

$$
\begin{gathered}
\operatorname{Earl}_{\mathrm{il}}-\operatorname{Tard}_{\mathrm{il}}=\mathrm{d}_{\mathrm{i}} \mathrm{Z}_{\mathrm{il}}-\mathrm{F}_{\mathrm{il}|\mathbf{S}|} ; \forall \mathrm{i} \in \mathrm{I}, \mathrm{l} \in \mathrm{L}_{\mathrm{i}} \\
\operatorname{Earl}_{\mathrm{il}}=\max \left(0, \mathrm{~d}_{\mathrm{i}} \mathrm{Z}_{\mathrm{il}}-\mathrm{F}_{\mathrm{il}|\mathbf{S}|}\right) ; \forall \mathrm{i} \in \mathrm{I}, \mathrm{l} \in \mathrm{L}_{\mathrm{i}} \\
\operatorname{Tard}_{\mathrm{il}}=\max \left(0, \mathrm{~F}_{\mathrm{il}|\mathbf{S}|}-\mathrm{d}_{\mathrm{i}} \mathrm{Z}_{\mathrm{il}}\right) ; \forall \mathrm{i} \in \mathrm{I}, \mathrm{l} \in \mathrm{L}_{\mathrm{i}} \\
\text { Flow }_{\mathrm{il}}=\mathrm{F}_{\mathrm{il}|\mathbf{S}|} \\
-\left[\mathrm{F}_{\mathrm{il} 1}-\sum_{\mathrm{j} \in \mathrm{JA}}\left(\mathrm{Ft}_{\mathrm{ij}} \mathrm{X}_{\mathrm{ilj}}+\mathrm{Pt}_{\mathrm{ij}} \mathrm{Bb}_{\mathrm{ilj}}\right)\right] ; \\
\forall \mathrm{i} \in \mathrm{I}, \mathrm{l} \in \mathrm{L}_{\mathrm{i}}
\end{gathered}
$$

Condition 9: Redundant Variable Eliminations. The redundant variables must be eliminated, Eqs. (21)-(24).

$$
\begin{gathered}
\mathrm{Z}_{\mathrm{il}}, \mathrm{Ba}_{\mathrm{il}}, \operatorname{Earl}_{\mathrm{il}}, \operatorname{Tard}_{\mathrm{il}}, \operatorname{Flow}_{\mathrm{il}}=0 ; \\
\mathrm{X}_{\mathrm{ilj}}, \mathrm{Bb}_{\mathrm{ilj}}=0 ; \forall \mathrm{i} \in \mathrm{I}, \mathrm{l} \geq \operatorname{Lmax}_{\mathrm{i}} \mathrm{l} \geq \operatorname{Lmax}_{\mathrm{i}}, \mathrm{j} \in \mathrm{J} \\
\mathrm{F}_{\mathrm{ils}}=0 ; \forall \mathrm{i} \in \mathrm{I}, \mathrm{l} \geq \operatorname{Lmax}_{\mathrm{i}}, \mathrm{s} \in \mathrm{S} \\
\mathrm{Y}_{\mathrm{ili}} \mathrm{I}^{\prime} \mathrm{l}^{\prime} \mathrm{s} \\
=0 ; \forall\left(\mathrm{i}, \mathrm{l}, \mathrm{i}^{\prime}, \mathrm{l}^{\prime}\right) \notin \mathrm{IL}, \mathrm{s} \in \mathrm{S}
\end{gathered}
$$


Condition 10: Binaries and Non-Negativities. The binary and non-negativity conditions are also expressed, Eqs. (25), (26).

$$
\begin{gathered}
\mathrm{Z}_{\mathrm{il}}, \mathrm{X}_{\mathrm{ilj}}, \mathrm{Y}_{\mathrm{ili}^{\prime} \mathrm{l}^{\prime} \mathrm{s}}=\{0,1\} \\
\mathrm{Ba}_{\mathrm{il}}, \mathrm{Bb}_{\mathrm{ilj}}, \mathrm{F}_{\mathrm{ils}}, \text { Earl }_{\mathrm{il}}, \text { Tard }_{\mathrm{il}}, \text { Flow }_{\mathrm{il}} \geq 0
\end{gathered}
$$

Condition 11: The OAPT. The OAPT is included in the model after the batches are selected and assigned to processing units. The processing times of batches are adjusted depending on the options to add special chemical into processing batches. The equations in condition 5 are modified with the term of proportional processing time reduction, Eqs. (27)-(29). Flow time in condition 8 is also adjusted accordingly, Eq. (30).

The chemical can be added to the batch $(i, l)$ when it is processed in assigned units of make-stage. Therefore, in unassigned units and for all operations that are not in make-stage chemical cannot be allowed to be added to the batch (i, l), Eq. (31).

$$
\begin{aligned}
& F_{i^{\prime} l^{\prime} s} \geq F_{i l s}+\sum_{j \in J A_{i^{\prime} s}}\left[F_{i^{\prime} j} X_{i^{\prime} l^{\prime} j}\right. \\
& \left.+\mathrm{Pt}_{\mathrm{i}^{\prime} \mathrm{j}} \mathrm{Bb}_{\mathrm{i}^{\prime} \mathrm{l}^{\prime} \mathrm{j}}\left(1-\mathrm{Pr}_{\mathrm{i}^{\prime}} \mathrm{AC}_{\mathrm{i}^{\prime} \mathrm{l}^{\prime} \mathrm{j}}\right)\right] \\
& +\mathrm{M}\left(1-\mathrm{Y}_{\mathrm{ili} \mathrm{i}^{\prime} \mathrm{l}^{\prime} \mathrm{s}}\right) ; \forall\left(\mathrm{i}, \mathrm{l}, \mathrm{i}^{\prime}, \mathrm{l}^{\prime}\right) \in \mathrm{IL}, \mathrm{s} \in \mathrm{S}
\end{aligned}
$$

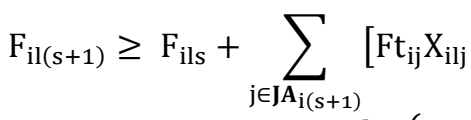

$$
\begin{aligned}
& \left.+\mathrm{Pt}_{\mathrm{ij}} \mathrm{Bb}_{\mathrm{ilj}}\left(1-\mathrm{Pr}_{\mathrm{i}} \mathrm{AC}_{\mathrm{ilj}}\right)\right] \text {; } \\
& \forall \in \mathrm{I}, \mathrm{l} \in \mathrm{L}_{\mathrm{i}}, \mathrm{s}<|\mathrm{S}|
\end{aligned}
$$

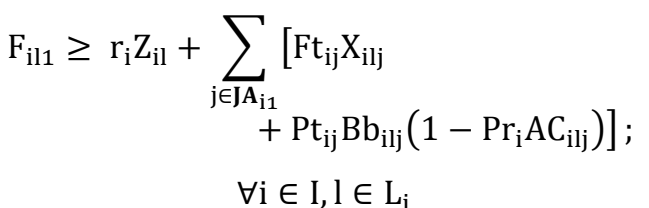

$$
\begin{aligned}
& -\left[\mathrm{F}_{\mathrm{il} 1}-\sum_{\mathrm{j} \in \mathrm{JA}_{\mathrm{i} 1}}\left[\mathrm{Ft}_{\mathrm{ij}} \mathrm{X}_{\mathrm{ilj}}+\mathrm{Pt}_{\mathrm{ij}} \mathrm{Bb}_{\mathrm{ilj}}\left(1-\mathrm{Pr}_{\mathrm{i}} \mathrm{AC}_{\mathrm{ilj}}\right)\right]\right] \text {; } \\
& \forall \mathrm{i} \in \mathrm{I}, \mathrm{l} \in \mathrm{L}_{\mathrm{i}} \\
& \mathrm{AC}_{\text {ilj }}=0 ; \quad \forall \mathrm{i} \in \mathrm{I}, \mathrm{l} \in \mathrm{L}_{\mathrm{i}}, \mathrm{j} \in \mathrm{j}: \\
& \mathrm{X}_{\mathrm{ilj}}=0 \cup(\mathrm{j} \notin \text { MakeStage })
\end{aligned}
$$

\subsection{Objective Functions of Models}

\subsubsection{Individual objectives}

There are four factors that are minimized individually to measure individual performance including total earliness (TEN), total tardiness (TTN), total flow time (TFT), and total processing cost (TPC). These factors are expressed as follows, Eqs. (32)-(35).

$$
\begin{aligned}
& \text { TEN }=\sum_{\mathrm{i} \in \mathbf{I}} \sum_{\mathrm{l} \in \mathbf{L}_{\mathrm{i}}} \operatorname{Earl}_{\mathrm{il}} \\
& \mathrm{TTN}=\sum_{\mathrm{i} \in \mathbf{I}} \sum_{\mathrm{l} \in \mathbf{L}_{\mathrm{i}}} \operatorname{Tard}_{\mathrm{il}}
\end{aligned}
$$

$$
\begin{aligned}
& \mathrm{TFT}=\sum_{\mathrm{i} \in \mathbf{I}} \sum_{\mathrm{l} \in \mathbf{L}_{\mathrm{i}}} \text { Flow }_{\mathrm{il}}
\end{aligned}
$$

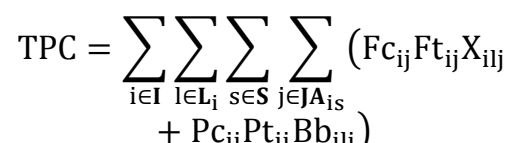

\subsubsection{Compromised objective}

Weighted average of satisfaction level (WASL) of all four factors is maximized to measure compromised performance, Eq. (36). The satisfaction level $\left(\mathrm{SL}_{\mathrm{f}}\right)$ of each factor is computed by Eq. (37) for minimized factors and Eq. (38) for maximized factors.

$$
\begin{gathered}
\text { WASL }=\sum_{\mathrm{f} \in \mathrm{F}} \mathrm{w}_{\mathrm{f}} \mathrm{SL}_{\mathrm{f}} \\
\mathrm{SL}_{\mathrm{f}}=\frac{\operatorname{Max}_{\mathrm{f}}-\mathrm{f}}{\operatorname{Max}_{\mathrm{f}}-\mathrm{Min}_{\mathrm{f}}} ; \quad \forall \mathrm{f} \in \mathrm{F} \\
\mathrm{SL}_{\mathrm{f}}=\frac{\mathrm{f}-\mathrm{Min}_{\mathrm{f}}}{\operatorname{Max}_{\mathrm{f}}-\mathrm{Min}_{\mathrm{f}}} ; \quad \forall \mathrm{f} \in \mathrm{F}
\end{gathered}
$$

When the OAPT is included in the model, the addition of chemical costs and reduction of proportional costs are accounted in the total processing cost expression, Eq. (39). The chemical is added to a processing batch to improve the performance measure of the system. Therefore, performance measure after adding chemical must be greater or equal to its initial value, Eq. (40).

$$
\begin{aligned}
\mathrm{TPC}=\sum_{\mathrm{i} \in \mathbf{I}} \sum_{\mathrm{l} \in \mathbf{L}_{\mathrm{i}} \sum_{\mathrm{s} \in \mathrm{S}}} \sum_{\mathrm{j} \in \mathrm{JA}_{\mathrm{is}}}\left[\mathrm{Fc}_{\mathrm{ij}} \mathrm{Ft}_{\mathrm{ij}} \mathrm{X}_{\mathrm{ilj}}\right. \\
+\mathrm{Pc}_{\mathrm{ij}} \mathrm{Pt}_{\mathrm{ij}} \mathrm{Bb}_{\mathrm{ilj}}\left(1-\mathrm{Pr}_{\mathrm{i}} \mathrm{AC}_{\mathrm{ilj}}\right) \\
\left.+\mathrm{Cc}_{\mathrm{i}} \mathrm{Bb}_{\mathrm{ilj}} \mathrm{AC}_{\mathrm{ilj}}\right]
\end{aligned}
$$

$$
\text { WASL } \geq \text { MaxWASL }
$$

Note that Eqs. (1)-(18), (21)-(26), and (32)-(35) are from Prasad and Maravelias (2008) and Sundaramoorthy and Maravelias (2008a, 2008b). Original ideas of this paper include Eqs. (19), (19a), (19b), (20), (27)-(31) and (36)-(40).

\section{Proposed Compromised Solution Method}

The proposed compromised solution method consists of three steps, (1) determining the best and worst values of each objective, (2) determining the initial compromised solution of all objectives when OAPT is not included in the model, and (3) determining the compromised solution with OAPT.

\subsection{Determining the Best and Worst Values}

The models are formulated and solved to find the optimal value of each objective. When an objective is optimized other objectives may not be optimal. The values of other objectives can be computed accordingly. The computed values of objectives can be improved by using a preemptive goal programming (PGP) (Massoud and Gupta, 2010). The PGP model assigns priorities to objectives and optimizes those objectives in the sequence of priorities. In this research, the PGP is useful to improve the worst case of computed value of each objective. There are two goals 
for PGP models in this step. The first goal is to optimize the first objective. Then a constraint is added in a manner that the value of the first objective is not worse than the obtained optimal value. Finally, the second goal which is the minimization of total tardiness (TTN) is used. However, when TTN is the first goal, the second goal is the minimization of total earliness (TEN).

The purpose of this step is to determine the best and the worst values of each objective. For each objective, the best value is the optimal value from first goal of PGP model, and the worst value is the worst of computed values that are resulted from second goal of PGP models. The PGP formulations for all objectives are summarized in Table 1.

\subsection{Determining the Initial Compromised Solution}

The best and the worst values of each objective that are obtained from PGP models in step 1 are used to compute the satisfaction level of each objective by using equations (37) and (38). Weights are assigned to the satisfaction level of each objective. Assigned weights represent the relative importance of these objectives. The highest weight means the most importance of that objective to the system, whereas the lowest weight means the least importance one.

The model is formulated and solved to find the optimal compromised objective. The weighted average of satisfaction level (WASL) is used as the compromised objective. The WASL is maximized with the constraints of equations (6)-(26), and (32)-(38). This step aims to determine the initial compromised solution when the OAPT is not included in the model.

\subsection{Determining the Compromised Solution with OAPT}

The initial compromised solution can be improved by including the OAPT in the model. In this case, the decisions of batch selection, batch sizing, and batch assignment must be the same as the solution from step 2 in order to keep the model linear.

The OAPT is applied to adjust the sequence and timing of each processing batch. The WASL is still used as compromised objective. The model includes maximization of WASL and the equations (12), (19), (21), (23)-(34), and (36)-(40) as constraints. The performance of this step (TPC) needs to be compared with the initial performance in step 2, using equation (39).

\section{A Case Study}

In this section, we considered a case of production plant that has six processing units and ten ordered demands. Three units are used for mixing (make-stage) and other three units are used for packing (pack-stage). The operational capacities, processing times, and processing costs of each unit are given in Table 2. Each order is provided with demand, release/due time, and forbidden units in each stage as shown in Table 3. The production system has no forbidden paths between processing units in make-stage and pack-stage.

From information in Tables 2 and 3, the minimum and maximum feasible batch sizes, and the minimum and maximum numbers of batches for each order can be determined in parameters preparation step, Eqs. (1)-(5), and used as parts of input parameters in the models (Table 4).

The effectiveness of PGP models that are introduced in step 1 of the proposed method will be evaluated in this section. Based on a viewpoint of decision maker, the weights for satisfaction levels are assigned as $15 \%$ for TEN, $50 \%$ for TTN, $15 \%$ for TFT, and $20 \%$ for TPC. This means that the total tardiness of jobs is the most important objective among all objectives. The total processing cost is significantly less important than the total tardiness. The total earliness and total flow time are equally and the least importance. The initial performance of compromised solution method will be compared to the performance of PGP models. When OAPT is used, the effect of cost-reduction-ratio (CRR) to the performance will be evaluated. The CRR is the ratio between chemical cost per $\mathrm{kg}$ of batch and percent reduction of processing time. The unit of CRR is "dollar per one kilogram of batch per one percent reduction of processing time". We set the percent reduction to be constant at $20 \%$ and the chemical costs are varied accordingly (Table 5). The models in the case study are solved by using CPLEX 12.4 on a desktop computer with a $3.30 \mathrm{GHz}$ Core(TM) i5-2500 CPU and 9.00 GB RAM running on 64-bit operating system of windows 7 .

Table 1. The summary of PGP formulated models

\begin{tabular}{|c|c|c|}
\hline Factor & 1st Goal & 2nd Goal \\
\hline \multirow[t]{3}{*}{ TEN } & Obj.: $\min$ TEN & Obj.: $\min$ TTN \\
\hline & St.: Eqs. (6)-(26), \& (32)-(35) & Given $\mathrm{Z}_{\mathrm{il}}, \mathrm{X}_{\mathrm{ilj}}, \mathrm{Bb}_{\mathrm{ilj}}, \operatorname{Earl}_{\mathrm{il}}$ \\
\hline & & St.: Eqs. (12)-(15), (19)-(21), (23)-(26), \& (32)-(35) \\
\hline \multirow[t]{3}{*}{ TTN } & Obj.: $\min$ TTN & Obj.: min TEN \\
\hline & St.: Eqs. (6)-(26), \& (32)-(35) & Given $\mathrm{Z}_{\mathrm{il}}, \mathrm{X}_{\mathrm{ilj}}, \mathrm{Bb}_{\mathrm{ilj}}, \operatorname{Tard}_{\mathrm{il}}$ \\
\hline & & St.: Eqs. (12)-(15), (19)-(21), (23)-(26), \& (32)-(35) \\
\hline \multirow[t]{3}{*}{ TFT } & Obj.: $\min$ TFT & Obj.: $\min \mathrm{TTN}$ \\
\hline & St.: Eqs. (6)-(18), (20)-(26), \& (32)-(35) & Given $\mathrm{Z}_{\mathrm{il}}, \mathrm{X}_{\mathrm{ilj}}, \mathrm{Bb}_{\mathrm{ilj}}$, Flow $\mathrm{il}$ \\
\hline & & St.: Eqs. (12)-(15), (19)-(21), (23)-(26), \& (32)-(35) \\
\hline \multirow[t]{3}{*}{ TPC } & Obj.: $\min$ TPC & Obj.: $\min$ TTN \\
\hline & St.: Eqs. (6)-(18), (20)-(26), \& (32)-(35) & Given $\mathrm{Z}_{\mathrm{il}}, \mathrm{X}_{\mathrm{ilj}}, \mathrm{Bb}_{\mathrm{ilj}}$ \\
\hline & & St.: Eqs. (12)-(15), (19)-(21), (23)-(26), \& (32)-(35) \\
\hline
\end{tabular}


54 Horng, S. and Yenradee, P.

Table 2. Operational capacities, processing times, and processing costs

\begin{tabular}{|c|c|c|c|c|c|c|}
\hline \multirow[b]{2}{*}{ Unit j } & \multicolumn{3}{|c|}{ Stage 1 (make) } & \multicolumn{3}{|c|}{ Stage 2 (pack) } \\
\hline & 1 & 2 & 3 & 4 & 5 & 6 \\
\hline $\operatorname{bmin}_{\mathrm{j}}(\mathrm{kg})$ & 30 & 25 & 30 & 20 & 30 & 25 \\
\hline $\operatorname{bmax}_{j}(k g)$ & 50 & 35 & 45 & 45 & 50 & 45 \\
\hline \multicolumn{7}{|l|}{ For $\forall \mathrm{i} \in \mathrm{I}$} \\
\hline $\mathrm{Ft}_{\mathrm{ij}}(\mathrm{hr} / \mathrm{setup})$ & 2.25 & 3.00 & 2.00 & 2.50 & 3.00 & 2.00 \\
\hline $\mathrm{Pt}_{\mathrm{ij}}(\mathrm{hr} / \mathrm{kg})$ & 0.20 & 0.30 & 0.25 & 0.15 & 0.15 & 0.15 \\
\hline $\mathrm{Fc}_{\mathrm{ij}}(\$ / \mathrm{hr})$ & 25.00 & 10.00 & 20.00 & 15.00 & 10.00 & 20.00 \\
\hline $\mathrm{Pc}_{\mathrm{ij}}(\$ / \mathrm{hr})$ & 13.05 & 7.00 & 10.00 & 10.00 & 10.00 & 10.00 \\
\hline
\end{tabular}

Table 3. The demands, release/due times, and forbidden units in each stage

\begin{tabular}{cccccc}
\hline Order $\mathrm{i}$ & $\mathrm{Q}_{\mathrm{i}}(\mathrm{kg})$ & $\mathrm{r}_{\mathrm{i}}(\mathrm{hr})$ & $\mathrm{d}_{\mathrm{i}}(\mathrm{hr})$ & $\mathrm{JF}_{\mathrm{i} 1}$ & $\mathrm{JF}_{\mathrm{i} 2}$ \\
\hline 1 & 75 & 0 & 48 & 3 & 6 \\
2 & 90 & 0 & 56 & 3 & 6 \\
3 & 120 & 0 & 80 & 3 & 6 \\
4 & 65 & 0 & 48 & 2 & 5 \\
5 & 90 & 0 & 80 & 2 & 5 \\
6 & 125 & 0 & 96 & 2 & 5 \\
7 & 65 & 0 & 56 & - & 4 \\
8 & 80 & 0 & 72 & - & 4 \\
9 & 95 & 0 & 96 & - & 4 \\
10 & 120 & 0 & 102 & - & 4 \\
\hline
\end{tabular}

Note: no forbidden path between make-stage and pack-stage.

Table 4. The feasible batch sizes and batch numbers

\begin{tabular}{ccccc}
\hline Order $\mathrm{i}$ & $\begin{array}{c}\mathrm{Bmin}_{\mathrm{i}} \\
(\mathrm{kg})\end{array}$ & $\begin{array}{c}\mathrm{Bmax}_{\mathrm{i}} \\
(\mathrm{kg})\end{array}$ & $\operatorname{Lmin}_{\mathrm{i}}$ & Lmax $_{\mathrm{i}}$ \\
\hline 1 & 25 & 50 & 2 & 3 \\
2 & 25 & 50 & 2 & 4 \\
3 & 25 & 50 & 3 & 5 \\
4 & 30 & 45 & 2 & 3 \\
5 & 30 & 45 & 2 & 3 \\
6 & 30 & 45 & 3 & 5 \\
7 & 25 & 50 & 2 & 3 \\
8 & 25 & 50 & 2 & 4 \\
9 & 25 & 50 & 2 & 4 \\
10 & 25 & 50 & 3 & 5 \\
\hline
\end{tabular}


Table 5. The CRR values and computed chemical costs

\begin{tabular}{ccccc}
\hline CRR & 0.025 & 0.030 & 0.035 & 0.040 \\
\hline $\operatorname{Pr}_{\mathrm{i}}(\%)$ & 20.00 & 20.00 & 20.00 & 20.00 \\
$\mathrm{Cc}_{\mathrm{i}}(\$ / \mathrm{kg})$ & 0.50 & 0.60 & 0.70 & 0.80 \\
\hline
\end{tabular}

\section{Results and Discussions}

The CPLEX program is set to record results when the models reach either optimal value or 3,600 seconds of running time by assuming that running time of 1 hour is long enough for CPLEX program to provide acceptable result. Note that, the objectives that are marked with the (*) symbol in Table 7 are those obtained after running CPLEX for 1 hour and the optimal solutions are still not obtained yet.

From Table 6, the results from running CPLEX models that are formulated in step 1 show that the single objective optimization models offer the optimal value of only the objective that is directly optimized. Other objectives that are not directly optimized are greatly worse. This means that when each objective is separately optimized the gap between the best and worst values of each objective is extensive. The PGP models, which can sequentially optimize objectives, can significantly reduce the gap between the best and the worst objective values

The best and worst values of each objective that are obtained from step 1 by using PGP models are parts of parameters in step 2 to determine the initial compromised solution. From Table 7, by comparing the performance of each objective to its best performance from step 1, the compromised solution method does not provide either the best or worst performance for any objective. Note that the compromised solution method gives the highest WASL which is the system performance compared with all of the PGP models. This method rather than optimizes the performance of each objective, it is trying to optimize the overall performance of the system.

Fig. 1 shows that the utilization of processing units in make-stage is very high for the compromised solution method. The machines are almost 100 percent utilized and just a few idle times all along the schedule. The order quantities are divided into batches with the most effective batch sizes for all orders and are assigned to the processing units that are the most suitable. The operations are not started at the beginning of the schedule period even if there is tardiness of some orders. If the operations are started at the beginning, both the earliness or flow time would be increased, and the overall performance can be dropped. The compromised solution method is trying to adjust the operations to the optimal timings that results in the best system performance.

In step 3 the OAPT is included in the models and the decisions of adding chemical to the processing batches in make-stage are considered. When the chemical is added to a processing batch in make-stage the processing time of that batch is reduced but the processing cost of that batch is increased depending on the different between the cost of added chemical and the reduction cost of proportional processing time. When the processing time of any batch is reduced the start and finish times of related operations are also shifted. The OAPT sometimes results in a change of the sequence of batches in processing units, for example, batches $(4,1)$ and $(4,2)$ in the third processing unit are switched.

The change of CRR is indicated by changing of chemical cost per unit of batch. When the chemical cost per unit of batch is reduced the CRR is also reduced. In Table 8 , if the table is observed from right to left of the compromised solution with OAPT column comparing to initial compromised solution, the results show that when the chemical cost per unit of batch is reduced, the addition of chemical cost (CC) is increased but the actual processing cost (PC) is reduced. The chemical cost and the processing cost affect the total processing cost (TPC). However, the total tardiness and the total flow time are significantly reduced. Therefore, the system performance (WASL) is considerably improved.

The proposed MILP model can generate a compromised solution among many conflicting objectives which is more practical than the optimal solution that considers only one objective at a time. In real life, managers need to consider many objectives simultaneously. Moreover, the model allows the manager to explore an option of adding special chemicals to reduce processing time of make-stage which can improve the system performances under some situations.

The proposed method uses the MILP model to solve for the optimal solution. Therefore, it can be used to solve practical industrial problems that have limited size. It may not be able to solve big problems in reasonable computational time. To apply this method to solve practical problems, some techniques to reduce problem size should be employed, e.g., reduction of number of batches and planning periods.

\section{Conclusions}

This paper developed the FCS system of make-and-pack production with multi-objectives and OAPT to determine the compromised solution for the system by using the weighted average of satisfaction level of all objectives as the performance indicator. The results from the case study can be concluded that the PGP models can narrow down the gap between the best and the worst performance of each objective when the best performances are the same as single objective optimization. The compromised solution method provides the highest overall performance compared with the PGP models but not the best performance of each objective. This method also generates a production schedule with relatively high utilization of each processing unit in make-stage. When the OAPT is used in the compromised solution method, the performance of the system is significantly improved and the degree of improvement is dependent on the chemical cost per unit of batch. When the chemical cost per unit of batch is lower, the addition of chemical is higher and the performance of the system is higher too.

The limitation of the proposed method is that the production schedule is applied only for continuous-time production. There is only single level of chemical option 
56 Horng, S. and Yenradee, P.

to be added. For further study, the system should be modified to be able to apply for discontinuous-time production that is used by most of small and medium production plants. The model should allow addition of multi-level of chemical to processing batch to reduce the batch processing time. The dynamic scheduling method that allows arrival of orders after the operations are started should also be considered.

\section{Acknowledgments}

The author would like to give a special thank to financial support from SIIT Scholarships for Students from Neighboring Countries - SIIT-SSNC-G-S2Y11/003.

Table 6. Gap difference between single objective optimizations and the PGP models

\begin{tabular}{|c|c|c|c|c|c|c|c|}
\hline \multirow{2}{*}{ Factor } & \multicolumn{3}{|c|}{ Single objective optimization } & \multicolumn{3}{|c|}{ The PGP models } & \multirow{2}{*}{$\frac{\text { Gap } 1}{\text { Gap } 2}$} \\
\hline & $\operatorname{Min}_{\mathrm{f}}$ & $\operatorname{Max}_{\mathrm{f}}$ & Gap 1 & $\operatorname{Min}_{\mathrm{f}}$ & $\operatorname{Max}_{\mathrm{f}}$ & Gap 2 & \\
\hline TEN (hr) & 0.00 & 306.44 & 306.44 & 0.00 & 259.66 & 259.66 & 1.18 \\
\hline TTN (hr) & 7.28 & 11300.50 & 11293.22 & 7.28 & 1227.75 & 1220.47 & 9.25 \\
\hline TFT (hr) & 426.00 & 1901.62 & 1475.62 & 426.00 & 964.38 & 538.38 & 2.74 \\
\hline TPC (\$) & 5253.00 & 6071.25 & 818.25 & 5253.00 & 6071.25 & 818.25 & 1.00 \\
\hline
\end{tabular}

Table 7. Performances for the PGP models and compromised solution (Comp.Sol.) method

\begin{tabular}{cccccc}
\hline $\begin{array}{c}\text { Factor } \\
\left(\mathrm{w}_{\mathrm{f}}\right)\end{array}$ & TEN then TTN & TTN then TEN & TFT then TTN & TPC then TTN & $\begin{array}{c}\text { Comp.Sol. } \\
\text { (Initial WASL) }\end{array}$ \\
\hline TEN $(\mathrm{hr})$ & 0.00 & 259.66 & 73.50 & 166.75 & 18.50 \\
$(0.15)$ & $(1.000)$ & $(0.000)$ & $(0.717)$ & $(0.358)$ & $(0.929)$ \\
TTN $(\mathrm{hr})$ & $* 465.00$ & $* 7.28$ & $* 1227.75$ & $* 440.25$ & 102.25 \\
$(0.50)$ & $(0.625)$ & $(1.000)$ & $(0.000)$ & $(0.645)$ & $(0.922)$ \\
TFT $(\mathrm{hr})$ & 964.38 & 656.03 & 426.00 & 637.37 & 579.75 \\
$(0.15)$ & $(0.000)$ & $(0.573)$ & $(1.000)$ & $(0.607)$ & $(0.714)$ \\
TPC $(\$)$ & 5761.50 & 5792.6 & 6071.25 & 5253.00 & 5417.75 \\
$(0.20)$ & $(0.379)$ & $(0.341)$ & $(0.000)$ & $(1.000)$ & $(0.799)$ \\
WASL & $(0.538)$ & $(0.654)$ & $(0.258)$ & $(0.667)$ & $*(0.867)$ \\
\hline
\end{tabular}

Table 8. Performance measures of compromised solution: initial and with OAPT

\begin{tabular}{|c|c|c|c|c|c|}
\hline \multirow{2}{*}{$\begin{array}{l}\text { Factor } \\
\left(\mathrm{w}_{\mathrm{f}}\right)\end{array}$} & \multirow{2}{*}{$\begin{array}{c}\text { Comp.Sol. } \\
\text { (Initial WASL) }\end{array}$} & \multicolumn{4}{|c|}{ Comp.Sol. with OAPT } \\
\hline & & $\mathrm{CRR}=0.025$ & $\mathrm{CRR}=0.030$ & $\mathrm{CRR}=0.035$ & $\mathrm{CRR}=0.040$ \\
\hline $\begin{array}{l}\text { TEN (hr) } \\
\quad(0.15)\end{array}$ & $\begin{array}{c}18.50 \\
(0.929)\end{array}$ & $\begin{array}{c}20.50 \\
(0.921)\end{array}$ & $\begin{array}{c}20.50 \\
(0.921)\end{array}$ & $\begin{array}{c}18.85 \\
(0.927)\end{array}$ & $\begin{array}{c}18.50 \\
(0.929)\end{array}$ \\
\hline $\begin{array}{l}\text { TTN (hr) } \\
\quad(0.50)\end{array}$ & $\begin{array}{l}102.25 \\
(0.922)\end{array}$ & $\begin{array}{c}88.20 \\
(0.934)\end{array}$ & $\begin{array}{c}90.75 \\
(0.932)\end{array}$ & $\begin{array}{l}103.30 \\
(0.921)\end{array}$ & $\begin{array}{l}102.25 \\
(0.922)\end{array}$ \\
\hline $\begin{array}{l}\text { TFT (hr) } \\
(0.15)\end{array}$ & $\begin{array}{l}579.75 \\
(0.714)\end{array}$ & $\begin{array}{l}480.70 \\
(0.898)\end{array}$ & $\begin{array}{l}500.40 \\
(0.862)\end{array}$ & $\begin{array}{l}534.20 \\
(0.799)\end{array}$ & $\begin{array}{l}567.15 \\
(0.738)\end{array}$ \\
\hline $\begin{array}{c}\mathrm{TPC}(\$) \\
(0.20)\end{array}$ & $\begin{array}{c}5417.75 \\
(0.799)\end{array}$ & $\begin{array}{c}5424.15 \\
(0.791)\end{array}$ & $\begin{array}{c}5476.15 \\
(0.727)\end{array}$ & $\begin{array}{c}5456.15 \\
(0.752)\end{array}$ & $\begin{array}{c}5431.05 \\
(0.782)\end{array}$ \\
\hline $\begin{array}{l}\mathrm{PC}(\$) \\
\mathrm{CC}(\$)\end{array}$ & 5417.75 & $\begin{array}{c}4979.15 \\
445.00\end{array}$ & $\begin{array}{c}5164.15 \\
312.00\end{array}$ & $\begin{array}{c}5351.15 \\
105.00\end{array}$ & $\begin{array}{c}5403.05 \\
28.00\end{array}$ \\
\hline WASL & $(0.867)$ & $(0.898)$ & $(0.879)$ & $(0.870)$ & $(0.868)$ \\
\hline
\end{tabular}




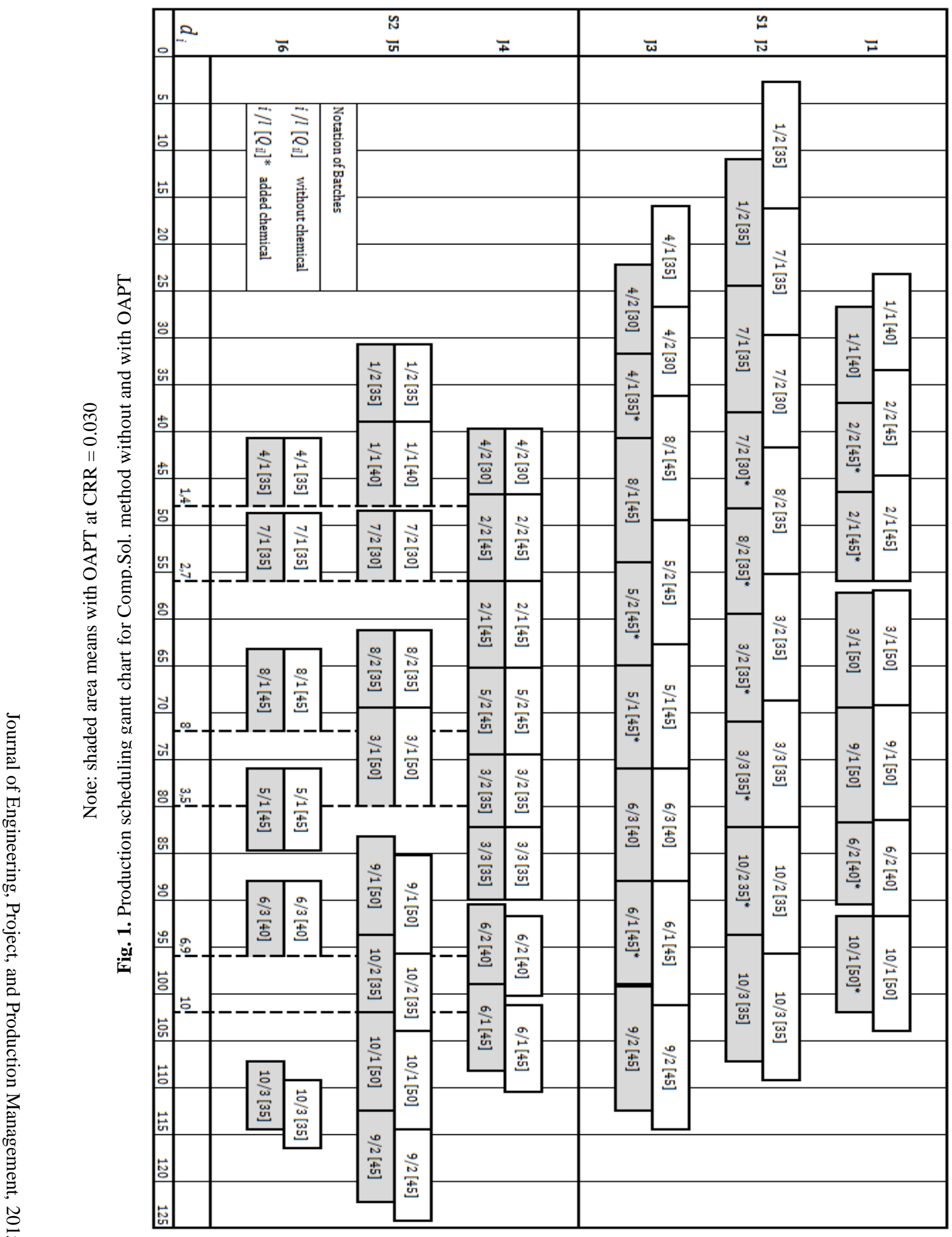

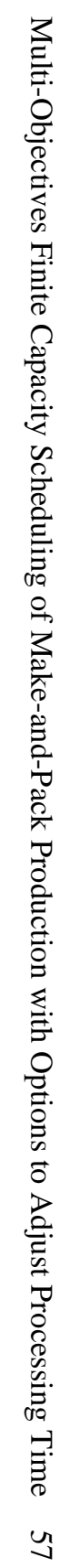




\section{References}

Baumann, P., and Trautmann, N. (2011). A continuoustime MILP to compute schedules with minimum changeover times for a make-and-pack production. Computer Aided Chemical Engineering, 29, 10601064.

Baumann, P., and Trautmann, N. (2013). A continuoustime MILP model for short-term scheduling of makeand-pack production processes. International Journal of Production Research, 51, 1707-1727.

Castro, P.M., and Grossmann, I.E. (2005). New continuous-time MILP model for the short-term scheduling of multistage batch plants. Industrial and Engineering Chemistry Research, 44, 9175-9190.

Castro, P.M., and Novais A.Q. (2008). Short-term scheduling of multistage batch plants with unlimited intermediate storage. Industrial and Engineering Chemistry Research, 47, 6126-6139.

Fündeling, C.-U., and Trautmann, N. (2006). Scheduling of make and pack plants: a case study. Computer Aided Chemical Engineering, 21, 1551-1556.

Günther, H.-O., Grunow, M. and Neuhaus, U. (2006). Realizing block planning concepts in make-and-pack production using MILP modeling and SAP APOC. International Journal of Production Research, 44, 3711-3726.

Honkomp S.J., Lombardo, S., Rosen, O. and Pekny, J.F. (2000). The curse of reality - why process scheduling optimization problems are difficult in practice. Computers and Chemical Engineering, 24, 323-328.

Ko, C.H., and Chen, Y.C. (2012). Evaluating production time buffer for precast fabrication. Journal of Engineering, Project, and Production Management, 2(2), 101-111.

Marchetti, P.A., Méndez, C.A. and Cerdá, J. (2012). Simultaneous lot sizing and scheduling of multistage batch processes handling multiple orders per product. Industrial and Engineering Chemistry Research, 51, 5762-5780.

Massoud, A.Z., and Gupta, S.M. (2010). Preemptive goal programming for solving the multi-criteria disassembly-to-order problem under stochastic yields, limited supply, and quantity discount. Proceeding of the 2010 Northeast Sciences Institute Conference, Alexandria, Virginia, 415-420.

Méndez, C.A., and Cerdá, J. (2002). An MILP-based approach to the short-term scheduling of make-andpack continuous production plants. OR Spectrum, 24, 403-429.

Méndez, C.A., Cerdá, J., Grossmann, I.E., Harjunkoski, I. and Fahl, M. (2006). State-of-the-art review of optimization methods for short-term scheduling of batch processes. Computers and Chemical Engineering, 30, 913-946.

Prasad, P., Maravelias, C.T. and Kelly, J. (2006). Optimization of aluminum smelter casthouse operations. Industrial and Engineering Chemistry Research, 45, 7603-7617.

Prasad, P., and Maravelias, C.T. (2008). Batch selection, assignment and sequencing in multi-stage multi- product processes. Computers and Chemical Engineering, 32, 1114-1127.

Sundaramoorthy, A., and Maravelias, C.T. (2008a). Simultaneous batching and scheduling in multistage multiproduct processes. Industrial and Engineering Chemistry Research, 47, 1546-1555.

Sundaramoorthy, A., and Maravelias, C.T. (2008b). Modeling of storage in batching and scheduling of multistage processes. Industrial and Engineering Chemistry Research, 47, 6648-6660.

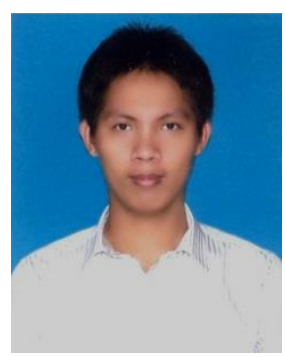

Mr. Sophea Horng is a Master Student in Logistics and Supply Chain Systems Engineering Program at Sirindhorn International Institute of Technology (SIIT), Thammasat University. He holds B.Eng. in Industrial Engineering from Sirindhorn International Institute of Technology (SIIT), Thammasat University. His research interests focus on production planning and inventory control systems, and finite capacity scheduling systems.

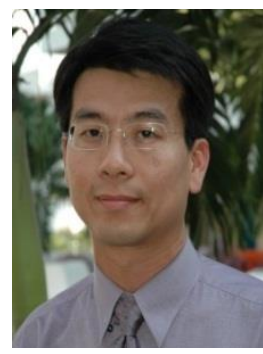

Dr. Pisal Yenradee is an Associate Professor in Industrial Engineering Program at Sirindhorn International Institute of Technology (SIIT), Thammasat University. He holds a B.Eng. in Production Engineering from King Mongkut's Institute of Technology and M.Eng. and D.Eng. in Industrial Engineering and Management from Asian Institute of Technology. His research interests focus on production planning and inventory control systems, JIT, ERP, TOC, finite capacity scheduling systems, aggregate production planning, master production scheduling, supply chain, and applied operations research. He has published papers in and served as a reviewer for many international journals. 